\title{
Persistence of the Misery Index in African Countries
}

\author{
Sakiru Adebola Solarin ${ }^{1} \cdot$ Luis A. Gil-Alana ${ }^{2}$. Carmen Lafuente ${ }^{3}$
}

Accepted: 21 August 2019 / Published online: 27 August 2019

(c) Springer Nature B.V. 2019

\begin{abstract}
This paper deals with the analysis of the misery index in a group of 55 African countries by using fractional integration or I(d) techniques. In doing so, we can measure the degree of persistence of the index in a more flexible way than with other methods that simply use integer degrees of differentiation (zero or one). Our results indicate a large degree of heterogeneity across the countries, with some showing short memory behaviour $(d=0)$; others long memory mean reverting behaviour $(0<\mathrm{d}<1)$ and others indicating the presence of unit roots $(d=1)$. Thus, shocks will have different effects depending on the country examined. Generally, we also find a positive relationship between the levels of persistence and income.
\end{abstract}

Keywords Misery index · Fractional integration · Persistency $\cdot$ African countries

JEL Classification B55 $\cdot$ C49 $\cdot$ N37

\section{Introduction}

The Misery Index, also known as the Economic Discomfort Index (EDI), was proposed by Okun in the 1970 s as a means to provide a simple but objective measure of discomfort. This index is obtained as the sum of the inflation rate plus the unemployment rate of an economy and can be considered as a reverse measure of economic well-being (Nessen 2008; Tang and Lean 2009). While the misery index can be regarded as a simple piece of construct, it provides a frugal way of appraising the character of the macroeconomy. The index is considered in the scientific community as a good approximation to determine the influence of a country's economic situation on consumer sentiment (Lovell and Tien 2000),

Unfavourable macroeconomic situations including high inflation and unemployment rates in developing nations, are likely to generate emigration to other countries (Akçay 2018). Over the years, authors have expanded the index to include several other macroeconomic variables (Barro 1999; Setterfield 2009). Supply side economics have offered

Luis A. Gil-Alana

alana@unav.es

1 Multimedia University, Bukit Beruang, Melaka, Malaysia

2 Faculty of Economics and ICS, University of Navarra, 31080 Pamplona, Spain

3 University Francisco de Vitoria, Madrid, Spain 
several solutions to combat the misery index, including tax incentives for savings, investment, and work; human capital investment; deregulation; trade liberalisation and infrastructure development.

Numerous studies have been conducted with the index (Tang and Lean 2009; Wolters and Tillmann 2015; Ali et al. 2015; Alam et al. 2016; Akçay 2018; Isoardi and Gil-Alana 2019; Albulescu and Tiwari 2018; Caporale and Gil-Alana 2018). One of the areas that has been neglected in the previous papers is the persistency of the misery index, which has several important implications. For example, persistency of the misery index means that it would take longer to revert to its long-run equilibrium after experiencing an economic shock. Hence, the magnitude of the uncertainty persistency will determine how large is the negative effect of the misery index on the economy. Therefore, the size of the persistency of the misery index will determine the extent of the remedial actions needed by the authorities to counter the negative effect of the misery index. Moreover, if misery index series are difference stationary at level, there is no chance of convergence between them (as they are at different levels) such that any inference of convergence on the relative uncertainty series is at best weak (Nieswiadomy and Strazicich 2004). The fact that the misery index series is persistent suggests that it is difficult to forecast future trends of misery index series based on their past values.

The aim of this paper is to make two important contributions to the existing papers on the misery index. One, we provide a seminal empirical investigation on the persistency of the misery index. Two, we use a fractional integration, which is more general than other standard methods that only consider integer degrees of differentiation. We have focussed on 55 countries in Africa for the period, 1977-2017 because the continent is among the regions with the highest inflation and unemployment rates. The global inflation rate was 2.19\% compared to the inflation rate in Sub-Saharan Africa which was 5.31\% in the same period (World Bank 2019). The global unemployment rate was $4.58 \%$ compared to the unemployment rate in Sub-Saharan Africa which was $7.31 \%$ in the same period (World Bank 2019). Weaker global growth and a slump in commodity prices eroded economic growth in many African countries, resulting in a high unemployment rate. Moreover, slower economies translated into weaker exchange rates which, in turn, resulted in higher consumer price inflation. The main conclusion of the paper indicates a high degree of heterogeneity in the results across countries. Thus, we find evidence of anti-persistence in a single country: Guinea-Bissau; evidence of short memory in a group of twenty-one countries; long memory though mean reverting patterns in another group of twenty-five countries, and finally, evidence of unit roots in eight countries. The results further suggest that persistence is positively associated with income level among the African countries. In other words, persistence is likely to increase as income per capita increases among the African countries.

The remainder of the paper is patterned as follows: Sect. 2 provides a brief overview of the methodology, which is premised on fractional integration. Section 3 presents the data; Sect. 4 displays the empirical results, while Sect. 5 concludes the paper.

\section{Literature Review}

The existing studies have considered persistence in the two traditional components of the misery index. Thus, for example, Bleaney and Francisco (2005) examined the estimated inflation persistence in 102 developing countries during 1984-2000. They showed that 
inflation persistence is particularly high in countries with severe inflationary problems. Other more current studies are Wolters and Tillmann (2015) and Isoardi and Gil-Alana (2019), investigating the degree of persistence in the inflation rates in US and Argentina, respectively.

There are also some papers that focus on inflation persistence in Africa, mainly in South Africa, using different sample periods and different methodologies. Rangasamy (2009) studied inflation persistence in South Africa since 1981 with an AutoRegressive Moving Average (ARMA) model, obtaining different measures of persistence in aggregate as well as in disaggregated data. He showed that inflation has been persistent until the year 2000. Balcilar et al. (2016) used a fractionally integrated ARMA (ARFIMA) model with a Markov-Switching parameter (MS-ARFIMA) in the study of inflation persistence in South Africa. Using monthly data for the time period 1923-2014, they showed that inflation is very persistent both when it is high and when is low, although it is more persistent in high inflation regimes. Gil-Alana (2011) showed that South African inflation is a covariance stationary process with long range dependence during the time period 1970: 01-2008: 12. He used fractional integration methods. Gupta et al. (2017) also studied South Africa's inflation persistence using quantile regressions. Their results for the time period 1975: 02-2015: 04 indicate that the size of inflation persistence vary for various quantiles across different monetary regimes, and the inflation persistence is close to the unit root in the upper quantiles. Phiri (2017) examined the changes in inflation before (2002: 01-2008: 06) and after (2008: 07-2016: 01) the global financial crisis. He showed that inflation persistence decreased after subprime crisis. Still in South Africa, Kabundi et al. (2019) showed that the persistence in inflation increased on the period 1944-2001, it remained constant from 2001 to 2008 and eventually increased around 2008.

Recent studies on unemployment persistence have also been found in the literature. García-Cintado et al. (2015), Albulescu and Tiwari (2018) and Gil-Alana et al. (2019) have examined the persistency of the unemployment rate, in Spain, Romania and Turkey, respectively. Kouassi and Sthlare (2018) found that, over the period 1991-2014, shocks to unemployment rate were generally permanent in countries such as South Africa. They also analysed the hysteresis in unemployment in Botswana and South Africa using panel unit root tests. Caporale and Gil-Alana (2018) analysed the unemployment in Africa. Using fractional integration, they examined the stochastic behaviour of unemployment in eleven African countries (Botswana, Ethiopia, Ghana, Kenya, Malawi, Mauritius, Nigeria, Senegal, South Africa, Tanzania and Zambia) from the 1960s until 2010, finding evidence against mean reversion in all series under examination. This suggests that hysteresis is a plausible hypothesis for unemployment in most African countries. Pikoko and Phiri (2018) also analysed hysteresis for eight categories of unemployment in South Africa using a battery of individual and panel unit root tests. Yaya et al. (2019) investigated the presence of unit roots in the unemployment rates of 42 African countries. Their results indicated that the hysteresis hypothesis holds only in seven countries (Algeria, Botswana, Cabo Verde, Congo Democratic Republic, Guinea-Bissau, Liberia and Tanzania).

Research on the misery index has mainly focused on the relationship, in terms of correlation and/or causality, between the misery index and other variables such as life satisfaction, health spending, economic misery, economic growth and good governance (Cavanaugh and King 1988; Welsch 2007; Tang and Lean 2009; Wu et al. 2014; Bentley et al. 2014; Marvasti et al. 2014; Rosas and Manzetti 2015; Ali et al. 2015; Alam et al. 2016; Shahbaz et al. 2016; Saboor et al. 2017; Akçay 2018; Dadgar and Nazari 2018).

There are very few studies on the misery index in Africa. Tule et al. (2017), based on the work by Cohen et al. (2014), focussed on the economic distress index (EDI) in the 
analysis of the optimal levels of inflation and unemployment. This technique relies on the expectations-augmented Phillips curve and Okun's law, distinguishing between the actual and natural rates of unemployment (Wiseman 1992). They decomposed the historical trend of poverty level between 2002Q1 and 2016Q4 in Nigeria as it relates to the level of unemployment, inflation and output.

The foregoing literature review demonstrates the following. Firstly, there is no study that has considered the persistency of the misery index. Secondly, the number of misery index papers on the African continent is limited. Thirdly, the use of fractional integration has not been employed so far in the analysis of persistence in misery indices.

\section{Methodology}

Unit root tests have been widely employed in the literature when dealing with persistence in time series data. Since the 80s, many test statistics have been proposed and improved in the context of unit roots, starting with Dickey and Fuller (ADF 1979) and followed by others such as Phillips and Perron (PP 1988), Kwiatkowski et al. (KPSS 1992), Elliot et al. (ERS 1996), Ng and Perron (NP 2001), etc.

However, it has been proved in recent years that many time series are not necessarily neither stationary $\mathrm{I}(0)$ nor nonstationary $\mathrm{I}(1)$ but may require fractional degrees of differentiation. In other words, the number of differences required to get stationary $\mathrm{I}(0)$ may not necessarily be an integer value (usually 1 ) but any real value, including fractional values, i.e. a series may be $\mathrm{I}(\mathrm{d})$ with $\mathrm{d}$ constrained between 0 and 1 , or even above 1 . Moreover, many authors have proved that standard unit root tests such as those mentioned above have extremely low power if the alternatives are of a fractional form (Diebold and Rudebusch 1991; Hasslers and Wolters 1994; Lee and Schmidt 1996 etc.). Thus, in this paper, we consider processes of form:

$$
(1-L)^{d} x_{t}=u_{t}, \quad t=1,2, \ldots,
$$

where $\mathrm{L}$ is the lag operator (i.e., $\mathrm{Lx}_{\mathrm{t}}=\mathrm{x}_{\mathrm{t}-1}$ ) and $\mathrm{d}$ can be any real value, and we estimate the differencing parameter $d$ with the Whittle function in the frequency domain (Dahlhaus 1989) by using a procedure of Robinson's (1994) that has several relevant features compared to other methods. First, it behaves well in finite samples (Gil-Alana and Robinson 1997) which is important taking into account the limited number of observations used in this application. More importantly, this method remains valid even in nonstationary contexts (i.e., $\mathrm{d} \geq 0.5$ ) and thus, it does not require preliminary differencing in the case of nonstationarity. Finally, it has a standard null limit distribution, and it is the most efficient method in the Pitman sense against local departures from the null.

Robinson (1994) proposed a test of the null hypothesis:

$$
\mathrm{H}_{\mathrm{o}}: \mathrm{d}=\mathrm{d}_{\mathrm{o}} \text {, }
$$

in the model given by Eq. (1), where $d_{o}$ can be any real value, and where $x_{t}$ can be the errors in a regression model of form:

$$
y_{t}=\beta_{0}+\beta_{1} t+x_{t},
$$

where $y_{t}$ is then the observed data. The test statistic is based on the Lagrange Multiplier principle and its functional form is:

$$
\hat{r}=\left(\frac{T}{\hat{A}}\right)^{1 / 2} \frac{\hat{a}}{\hat{\sigma}^{2}},
$$


where $\mathrm{T}$ is the sample size and

$$
\begin{aligned}
& \hat{a}=\frac{2 \pi}{T} \sum_{j=1}^{T-1} \psi\left(\lambda_{j}\right) g\left(\lambda_{j} ; \hat{\tau}\right)^{-1} I\left(\lambda_{j}\right) \\
& \hat{A}=\frac{2}{T}\left(\sum_{j=1}^{T-1} \psi\left(\lambda_{j}\right)^{2}-\sum_{j=1}^{T-1} \psi\left(\lambda_{j}\right) \hat{\varepsilon}\left(\lambda_{j}\right)^{T} x\left(\sum_{j=1}^{T-1} \hat{\varepsilon}\left(\lambda_{j}\right) \hat{\varepsilon}\left(\lambda_{j}\right)^{T}\right)^{-1} \sum_{j=1}^{T-1} \hat{\varepsilon}\left(\lambda_{j}\right) \psi\left(\lambda_{j}\right)\right), \\
& \psi\left(\lambda_{j}\right)=\log \left|2 \sin \frac{\lambda_{j}}{2}\right| ; \quad \hat{\varepsilon}\left(\lambda_{j}\right)=\frac{\partial}{\partial \tau} \log g\left(\lambda_{j} ; \hat{\tau}\right) ; \quad \lambda_{j}=\frac{2 \pi j}{T} . \\
& \hat{\sigma}^{2}=\sigma^{2}(\hat{\tau})=\frac{2 \pi}{T} \sum_{j=1}^{T-1} g\left(\lambda_{j} ; \hat{\tau}\right)^{-1} I\left(\lambda_{j}\right)
\end{aligned}
$$

$\mathrm{g}\left(\lambda_{\mathrm{j}} ; \tau\right)$ is a known function derived from the spectral density of $\mathrm{u}_{\mathrm{t}}$, i.e., $\mathrm{f}\left(\left(\lambda_{\mathrm{j}} ; \tau\right)=\sigma^{2} / 2 \pi\right.$ $\mathrm{g}\left(\lambda_{\mathrm{j}} ; \tau\right)$; thus, in case of white noise $\mathrm{u}_{\mathrm{t}},\left(\lambda_{j} ; \tau\right)=\sigma^{2} / 2 \pi$, and $\mathrm{g}=1$, and $\hat{\tau}=\arg \min \sigma^{2}\left(\tau_{j}\right)$, and $\mathrm{I}(\lambda \mathrm{j})$ is the periodogram of $u_{t}=x_{t}-\hat{\beta}_{0}-\hat{\beta}_{1} t$, where $\hat{\beta}_{0}$ and $\hat{\beta}_{1}$ are the least squares estimates of $\beta$ in (3):

$$
I\left(\lambda_{j}\right)=\frac{1}{\sqrt{2 \pi T}}\left|\sum_{j=1}^{T-1} \hat{u}_{t} e^{i \lambda_{j} t}\right|^{2} .
$$

Under the null hypothesis (2), Robinson (1994) showed that

$$
\hat{\mathrm{r}} \rightarrow_{\mathrm{d}} \mathrm{N}(0,1) \text { as } \mathrm{T} \rightarrow \infty,
$$

where “ $\rightarrow$ " " stands for convergence in distribution. This standard limit behavior is a special feature of this test compared with the standard unit root methods where critical values have to be computed numerically on a case-by-case simulation study. Moreover, the limit behaviour holds independently of the specific modelling assumptions for the $I(0)$ disturbances $u_{t}$ in (1) in contrast to what happens in many other testing procedures (Phillips and Schmidt 1992).

As in other standard large-sample testing situations, the same limit behaviour can be obtained with other methods based on the Wald and LR tests (see, e.g. Lobato and Velasco 2007) though this clearly requires a consistent estimate of $d$, a condition that is not required with the LM test proposed here (for more details of this procedure, see Robinson 1994; Gil-Alana and Robinson 1997).

\section{Data and Empirical Results}

We have defined the misery index as the unweighted sum of the inflation and unemployment rates in this study. The data for the unemployment rate has been generated from Euromonitor International. Due to data constraints we have concentrated on 55 African countries. The list of the selected countries are in presented in Table 1, where it is shown that the Congo Democratic Republic, Angola, South Sudan, Zambia and Uganda have the highest average misery indexes over the sample period. These countries are also among the 
Table 1 Sample of countries and abbreviations

\begin{tabular}{llllll}
\hline Abbrev. & Country & Abbrev. & Country & Abbrev. & Country \\
\hline ALG & Algeria & GAB & Gabon & REU & Réunion \\
ANG & Angola & GAM & Gambia & RWA & Rwanda \\
BEN & Benin & GHA & Ghana & SAO & Sao Tomé \& Príncipe \\
BOT & Botswana & GUI & Guinea & SEN & Senegal \\
BUR & Burkina Faso & GUIB & Guinea-Bissau & SEY & Seychelles \\
BURU & Burundi & KEN & Kenya & SIE & Sierra Leone \\
CAM & Cameroon & LES & Lesotho & SOM & Somalia \\
CAP & Cape Verde & LIB & Liberia & SOU & South Africa \\
CEN & Central African Republic & LIBY & Libya & SOUS & South Sudan \\
CHAD & Chad & MAD & Madagascar & SUD & Sudan \\
COM & Comoros & MAL & Malawi & SWA & Swaziland \\
CONG & Congo Democratic Republic & MALI & Mali & TAN & Tanzania \\
CONGB & Congo-Brazzavile & MAU & Mauritania & TOG & Togo \\
COT & Côte d'Ivoire & MAUR & Mauritius & TUN & Tunisia \\
DJI & Djibouti & MOR & Morocco & UGA & Uganda \\
EGY & Egypt & MOZ & Mozambique & ZAM & Zambia \\
EQU & Equatorial Guinea & NAM & Namibia & ZIM & Zimbabwe \\
ERI & Eritrea & NIG & Niger & & \\
ETH & Ethiopia & NIGE & Nigeria & & \\
\hline
\end{tabular}

biggest in terms of volatility of the index as shown by their standard deviations. All return series are non-normally distributed, and a descriptive analysis of the countries is given in Table 2.

The first thing we do is to consider the following model,

$$
\mathrm{y}_{\mathrm{t}}=\beta_{0}+\beta_{1} t+x_{\mathrm{t}} ; \quad(1-L)^{d} x_{t}=u_{t}, \quad t=0,1, \ldots,
$$

where $y_{t}$ is the observed time series (misery index); $\beta_{0}$ and $\beta_{1}$ are unknown coefficients referring respectively to an intercept and a linear time trend, and $x_{t}$ is supposed to be $I(d)$ where $d$ can be any real value, and $u_{t}$ is $I(0)$ expressed in terms of a white noise process. ${ }^{1}$

We first computed the estimated values of $d$ (and the 95\% confidence bands of the nonrejection values of d using Robinson's (1994) tests, under the three standard cases of (1) no deterministic terms [i.e., $\beta_{0}=\beta_{1}=0$ in (5)], (2) an intercept $\left(\beta_{1}=0\right)$, and (3) an intercept with a linear time trend $\left(\beta_{0}\right.$ and $\beta_{1}$ estimated from the data), and select the model for each series based on the t-values on the estimated coefficients of the differenced processes.

Table 3 displays the estimated coefficients for each series. The first thing we observe in the table is that the time trend is statistically significant in 20 out of the 55 countries examined, namely: Burundi, Cameroon, Cape Verde, Comoros, Congo-Brazzavile, Côte d'Ivoire, Djibouti, Ghana, Guinea-Bissau, Lesotho, Madagascar, Mauritania, Mauritius, Morocco, Namibia, Niger, Senegal, Somalia, Swaziland and Togo, and in all cases, except for Guinea-Bissau, the time trend coefficient is found to be negative. If we focus on the

\footnotetext{
1 Allowing for autocorrelated erors throughout the model of Bloomfield (1973) produced qualitatively the same type of results as those reported in this work.
} 


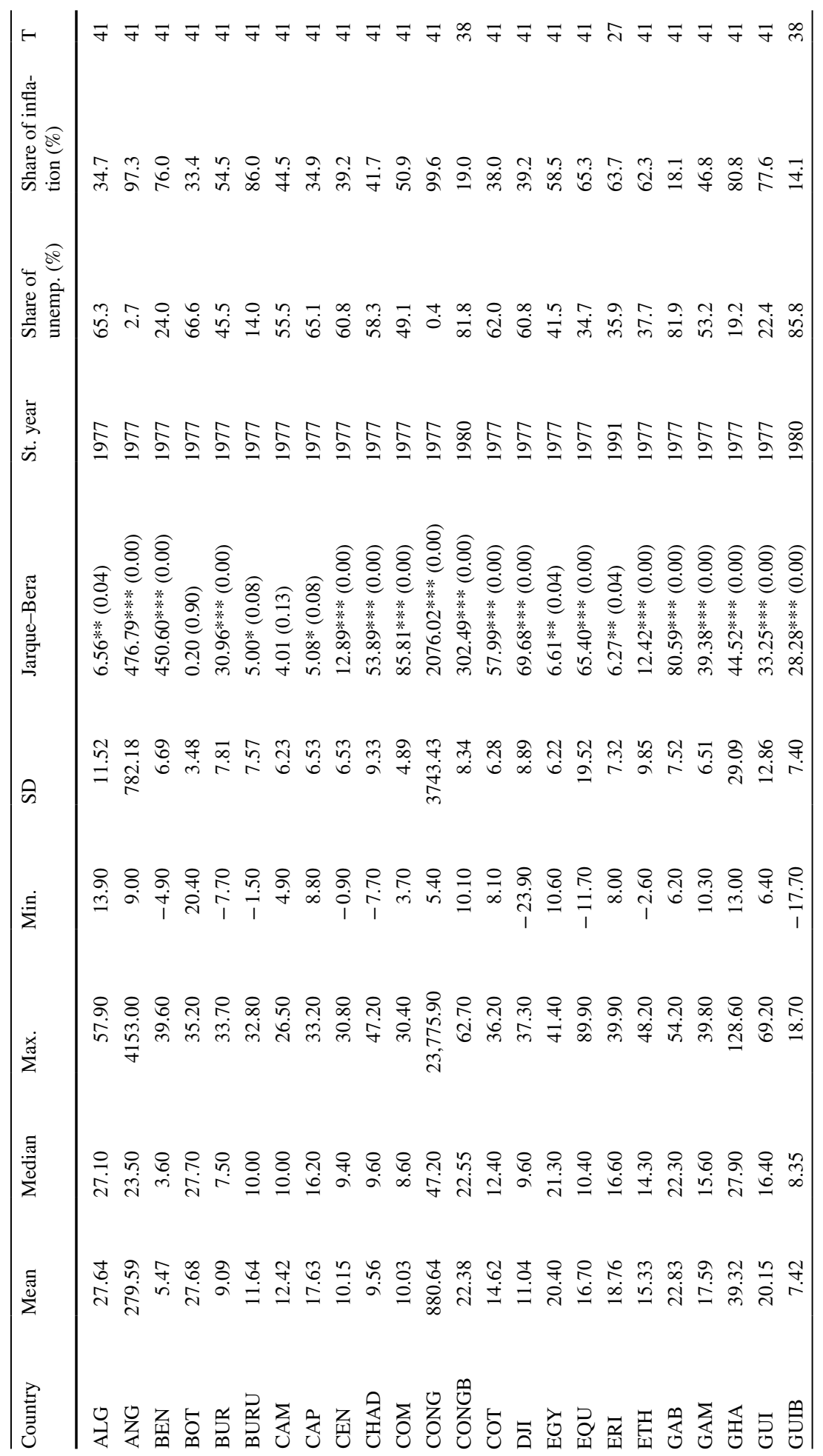




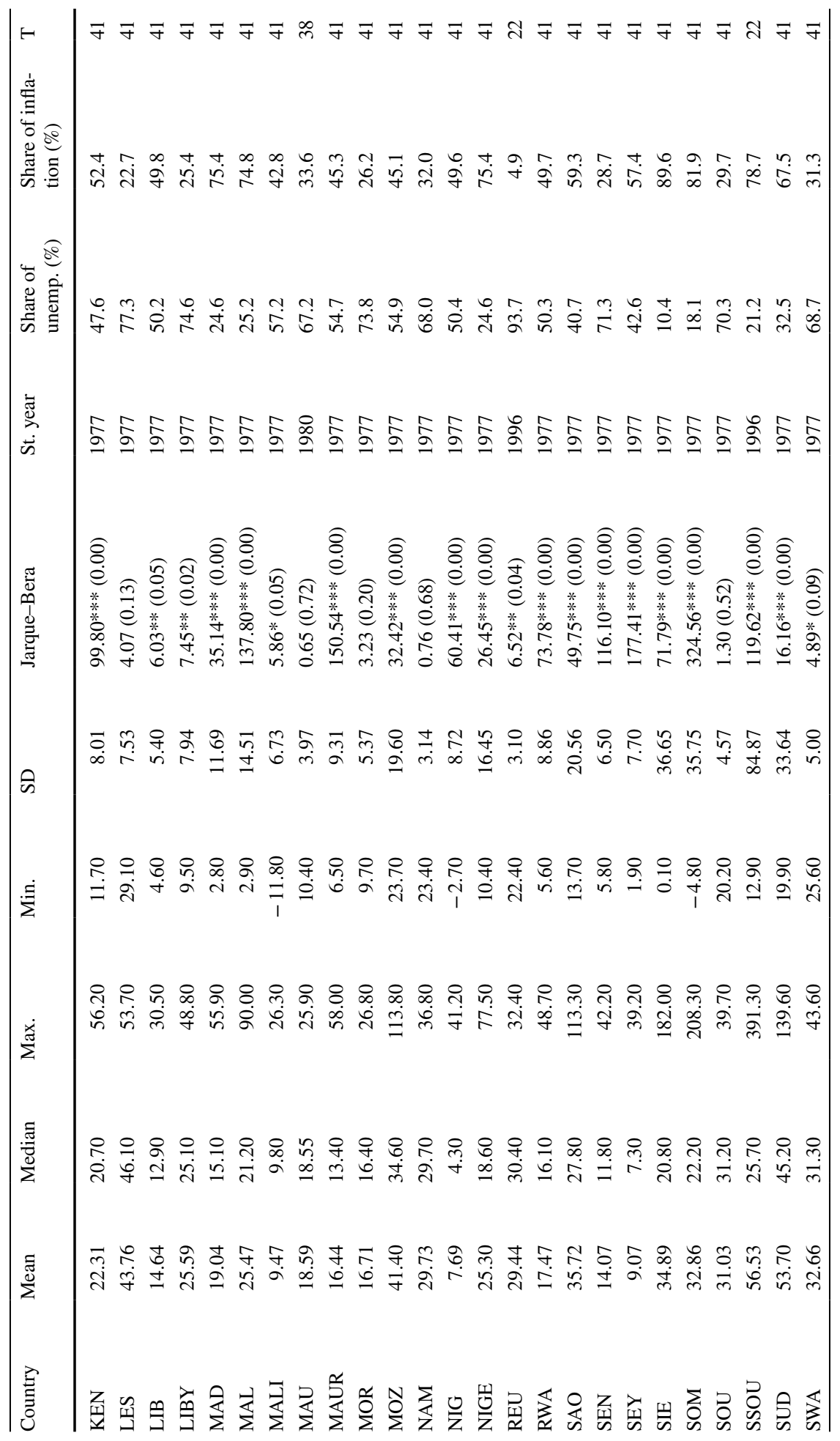




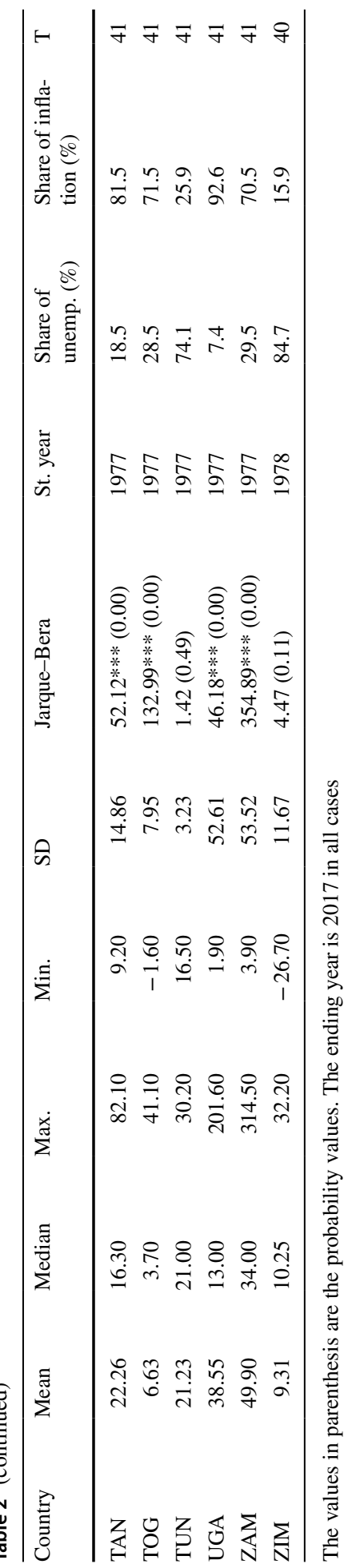


Table 3 Estimated coefficients for the selected model

\begin{tabular}{|c|c|c|c|}
\hline $\begin{array}{l}\text { Abbreviation (Coun- } \\
\text { tries) }\end{array}$ & No terms & An intercept & A linear time trend \\
\hline ALG & $0.96(0.77,1.28)$ & $27.008(5.16)$ & - \\
\hline ANG & $0.50(0.27,0.87)$ & $132.766(0.29)$ & - \\
\hline BEN & $0.05(-0.21,0.39)$ & $5.474(4.55)$ & - \\
\hline BOT & $0.64(0.41,0.95)$ & $29.374(14.70)$ & - \\
\hline BUR & $0.00(-0.17,0.25)$ & $14.077(6.15)$ & $-0.237(-2.59)$ \\
\hline BURU & $-0.14(-0.38,0.27)$ & $11.599(15.92)$ & - \\
\hline CAM & $0.40(-0.09,0.99)$ & $21.541(8.58)$ & $-0.419(-4.00)$ \\
\hline CAP & $0.44(0.19,0.83)$ & $27.483(11.06)$ & $-0.445(-4.17)$ \\
\hline CEN & $0.11(-0.16,0.49)$ & $10.296(7.16)$ & - \\
\hline CHAD & $-0.35(-0.63,0.04)$ & $9.730(22.58)$ & - \\
\hline $\mathrm{COM}$ & $-0.08(-0.30,0.26)$ & $14.263(12.98)$ & $-0.202(-4.32)$ \\
\hline CONG & $0.08(-0.10,0.33)$ & $839.62(1.12)$ & - \\
\hline CONGB & $0.26(0.05,0.58)$ & $27.818(6-79)$ & $-0.311(-1.77)$ \\
\hline COT & $0.31(-0.01,0.81)$ & $23.493(7.63)$ & $-0.362(-2.93)$ \\
\hline DJI & $0.29(0.070 .62)$ & $21.217(4.62)$ & $-0.393(-2.14)$ \\
\hline EGY & $0.46(0.23,0.82)$ & $19.600(6.40)$ & - \\
\hline EQU & $0.41(0.15,0.85)$ & $18.869(2.01)$ & - \\
\hline ERI & $0.43(0.16,0.89)$ & $15.1^{\circ} 49(4-11)$ & - \\
\hline ETH & $0.22(0.01,0.57)$ & $15.789(5.26)$ & - \\
\hline GAB & $0.10(-0.15,0.53)$ & $23.005(14.68)$ & - \\
\hline GAM & $0.64(0.39,1.09)$ & $20.012(4.77)$ & - \\
\hline GHA & $0.05(-0.11,0.30)$ & $72.584(9.24)$ & $-1.587(-4.94)$ \\
\hline GUI & $0.64(0.43,0.94)$ & $13.184(1.58)$ & - \\
\hline GUIB & $-0.71(-1.19,-0.19)$ & $5.047(12.90)$ & $0.131(5.73)$ \\
\hline KEN & $0.46(0.18,0.90)$ & $23.172(5.35)$ & - \\
\hline LES & $0.33(0.14,0.62)$ & $53.982(23.55)$ & $-0.517(-5.59)$ \\
\hline LIB & $0.65(0.45,1.03)$ & $19.144(6.20)$ & - \\
\hline LIBY & $0.37(0.17,0.65)$ & $27.531(7.62)$ & - \\
\hline MAD & $0.14(-0.18,0.64)$ & $25.871(5.65)$ & $-0.348(-1.90)$ \\
\hline MAL & $0.38(0.16,0.80)$ & $23.466(3.53)$ & - \\
\hline MALI & $0.19(-0.05,0.56)$ & $9.798(5.18)$ & - \\
\hline MAU & $0.26(0.08,0.54)$ & $21.634(12.06)$ & $-0.185(-2.41)$ \\
\hline MAUR & $0.50(0.29,0.81)$ & $27.573(5.54)$ & $-0.473(-2.09)$ \\
\hline MOR & $0.25(-0.02,0.59)$ & $25.540(25.21)$ & $-0.411(-10.21)$ \\
\hline $\mathrm{MOZ}$ & $0.53(0.36,0.78)$ & $33.659(3.13)$ & - \\
\hline NAM & $-0.05(-0.51,0.67)$ & $33.179(47.91)$ & $-0.164(-5.64)$ \\
\hline NIG & $0.23(-0.04,0.62)$ & $15.259(3.73)$ & - \\
\hline NIGE & $0.57(0.28,1.12)$ & $23.513(2.21)$ & - \\
\hline REU & $1.00(0.80,1.26)$ & $29.799(23.20)$ & - \\
\hline RWA & $0.51(0.20,0.96)$ & $18.436(3.42)$ & - \\
\hline SAO & $0.54(0.37,0.81)$ & $27.566(2.33)$ & - \\
\hline SEN & $0.08(-0.25,0.49)$ & $18.513(8.21)$ & $-0.209(-2.29)$ \\
\hline SEY & $0.32(0.01,0.89)$ & $10.031(3.23)$ & - \\
\hline SIE & $0.50(0.36,0.73)$ & $27.642(1.87)$ & - \\
\hline
\end{tabular}


Table 3 (continued)

\begin{tabular}{llll}
\hline $\begin{array}{l}\text { Abbreviation (Coun- } \\
\text { tries) }\end{array}$ & No terms & An intercept & A linear time trend \\
\hline SOM & $0.23(0.00,0.56)$ & $54.479(3.47)$ & $-1.158(-1.85)$ \\
SOU & $0.72(0.42,1.16)$ & $22.514(8.26)$ & - \\
SSOU & $0.42(0.01,0.81)$ & $66.355(1.72)$ & - \\
SUD & $0.85(0.66,1.06)$ & $41.991(2.21)$ & - \\
SWA & $-0.04(-0.22,0.22)$ & $38.866(38.63)$ & $-0.296(-7.01)$ \\
TAN & $0.48(0.35,0.70)$ & $20.331(2.84)$ & - \\
TOG & $0.10(-0.21,0.54)$ & $11.156(3.74)$ & $-0.210(-1.75)$ \\
TUN & $0.68(0.55,0.90)$ & $23.205(15.63)$ & - \\
UGA & $0.79(0.54,1.20)$ & $65.857(2.07)$ & - \\
ZAM & $0.49(0.33,0.72)$ & $43.206(1.53)$ & - \\
ZIM & $0.00(-0.22,0.37)$ & $9.002(5.16)$ & - \\
\hline
\end{tabular}

The values in parenthesis in the last two columns are t-values

estimated values of $d$, we observe that there is a single country, Guinea Bissau, with a significantly negative value of $d$, implying anti-persistence behaviour; short memory or I $(0)$ patterns are observed in another group of 21 countries: Chad $(-0.35)$, Burundi $(-0.14)$, Comoros (-0.08), Namibia (-0.05), Swaziland (-0.04), Burkina Faso (0.00), Zimbabwe (0.00), Benin (0.05), Ghana (0.05), Senegal (0.08), Congo D. Rep. (0.08), Gabon (0.10), Togo (0.10), Central African Republic (0.11), Madagascar (0.14), Mali (0.19), Somalia (0.23), Niger (0.23), Morocco (0.25), Côte d'Ivoire (0.31), Cameroon $(0.40) .^{2}$ More persistent, though still mean reverting patterns are detected in another group of countries: Ethiopia (0.22), Mauritania (0.26), Congo-Brazzavile (0.26), Djibouti (0.29), Seychelles (0.32), Lesotho (0.33), Libya (0.37), Malawi (0.38), Equatorial Guinea (0.41), South Sudan (0.42), Eritrea (0.43), Cape Verde (0.44), Kenya (0.46), Egypt (0.46), Tanzania (0.48), Zambia (0.49), Mauritius (0.50), Sierra Leone (0.50), Angola (0.50), Rwanda (0.51), Mozambique (0.53), Sao Tomé and Príncipe (0.54), Botswana (0.64), Guinea (0.64), and Tunisia (0.68); finally, lack of mean reversion or I(1) behaviour is found in the following cases: Nigeria (0.57), Gambia (0.64), Liberia (0.65), South Africa (0.72), Uganda (0.79), Sudan (0.85), Algeria (0.96), and Réunion (1.00).

A summary of the results is reported in Table 4 . We observe a single country with evidence of anti-persistence behaviour $(d<0)$. A group of twenty-one countries with short memory $(d=0)$ patterns; another group of twenty-five countries with long memory mean reverting behaviour $(0<\mathrm{d}<1)$ and finally, a group of eight countries where the unit root hypothesis $(\mathrm{d}=1)$ cannot be rejected.

As a robustness method, we also estimated $d$ with a semiparametric approach (the local Whittle method in Robinson 1995). The results, though not reported, are available from the authors upon request, and though, quantitatively, there are some small differences, generally, qualitatively the same results as those reported in Table 4 hold, finding evidence of anti-persistence in the case of Guinea Bissau, and evidence of unit roots for Liberia, South Africa, Uganda, Sudan, Algeria and Reunion, i.e., in the same countries as with

\footnotetext{
${ }^{2}$ In all these cases the $95 \%$ confidence intervals include the value $\mathrm{d}=0$.
} 
Table 4 Summary of the results for $\mathrm{d}$

\begin{tabular}{|c|c|c|c|}
\hline \multicolumn{4}{|l|}{$\mathrm{d}<0$ (Anti-persistence) } \\
\hline \multicolumn{4}{|l|}{ Guinea-Bissau (-0.71) } \\
\hline \multicolumn{4}{|c|}{$\mathrm{d}=0$ (Short memory or $\mathrm{I}(0)$ behaviour $)$} \\
\hline Chad $(-0.35)$ & Benin $(0.05)$ & & Madagascar (0.14) \\
\hline Burundi $(-0.14)$ & Ghana (0.05) & & Mali (0.19) \\
\hline Comoros $(-0.08)$ & Senegal (0.08) & & Somalia $(0.23)$ \\
\hline Namibia $(-0.05)$ & Congo Democratic Republic (0.08) & & Niger $(0.23)$ \\
\hline Swatziland $(-0.04)$ & Gabon $(0.10)$ & & Morocco $(0.25)$ \\
\hline Burkina Faso $(0.00)$ & Togo $(0.10)$ & & Côte d'Ivoire (0.31) \\
\hline Zimbawe (0.00) & Central African Republic (0.11) & & Cameroon $(0.40)$ \\
\hline \multicolumn{4}{|c|}{$0<\mathrm{d}<1$ (Fractional integration, long memory or I(d) behaviour) } \\
\hline Ethiopia $(0.22)$ & South Sudan (0.42) & & Angola $(0.50)$ \\
\hline Mauritania $(0.26)$ & Eritrea $(0.43)$ & & Rwanda (0.51) \\
\hline Congo-Brazzavile (0.26) & Cape Verde (0.44) & & Mozambique (0.53) \\
\hline Djibouti $(0.29)$ & Kenya $(0.46)$ & & Sao Tome $(0.54)$ \\
\hline Seychelles (0.32) & Egypt (0.46) & & Botswana (0.64) \\
\hline Lesotho (0.33) & Tanzania $(0.48)$ & & Guinea (0.64) \\
\hline Libya (0.37) & Zambia (0.49) & & Tunisia (0.68) \\
\hline Malawi (0.38) & Mauritius (0.50) & & \\
\hline Equatorial Guinea (0.41) & Sierra Leone (0.50) & & \\
\hline \multicolumn{4}{|l|}{$\mathrm{d}=1$ (I(1) behaviour) } \\
\hline Nigeria (0.57) & & Uganda (0.79) & \\
\hline Gambia (0.64) & & Sudan (0.85) & \\
\hline Liberia $(0.65)$ & & Algeria (0.96) & \\
\hline South Africa (0.72) & & Reunion (1.00) & \\
\hline
\end{tabular}

the parametric method, the only differences referring to the cases with values constrained between 0 and $1 .^{3}$

As a final issue in the paper we look at the potential relationship between the degree of persistence in the misery index and the degree of economic development. For this purpose, we have grouped the countries in Table 5 according to their level of income. This figure shows four groups of countries according to GDP per capita (IMF 2018) corresponding to each of the four quartiles: low income $(\mathrm{Q} 1)$, lower-middle income $(\mathrm{Q} 2)$, upper-middle income $(\mathrm{Q} 3)$ and high income $(\mathrm{Q} 4)$; and we have related them to the persistence of the index of misery ("d" values). Figure 1 represents the two variables observing a significant positive relationship between income and the degree of persistence in the misery index.

One reason for the results in favour of mean reverting cases of misery index in several African countries can be attributed to the stationarity of GDP. Studies have established that the the GDP of many African countries are stationary (Ying et al. 2014; Solarin and Anoruo 2015). Since GDP is one of the most important determinants of misery index and the most straightforward means to mitigate (economic hardship and discomfort, which is captured by) misery index is economic growth (Hanke 2017), the index is also expected to be stationary. The changes in the index over time and in different countries is a reflection of the changes in a country's economic performance.

\footnotetext{
3 We have also tested the persistence of the weighted misery index proposed by Di Tella et al. (2001) and the results are qualitatively similar to the output obtained in Table 4. They are available from the authors upon request.
} 
Table 5 Countries's income and persistence

\begin{tabular}{|c|c|c|}
\hline $\mathrm{d}=0$ & $0<\mathrm{d}<1$ & $\mathrm{~d}=1$ \\
\hline \multicolumn{3}{|l|}{ Low-income } \\
\hline Burundi & Malawi & Liberia \\
\hline Burkina faso & Mozambique & Uganda \\
\hline Central African Republic & 7 & \\
\hline Congo D. Rep. & South Sudan & \\
\hline \multicolumn{3}{|l|}{ Madagascar } \\
\hline \multicolumn{3}{|l|}{ Niger } \\
\hline \multicolumn{3}{|l|}{ Somalia } \\
\hline \multicolumn{3}{|l|}{ Togo } \\
\hline \multicolumn{3}{|l|}{ Lower-middler income } \\
\hline Benin & Tanzania & Gambia \\
\hline Comoros & Rwanda & Sudan \\
\hline Chad & Ethiopia & \\
\hline Mali & Eritrea & \\
\hline Zimbabwe & $\begin{array}{l}\text { Guinea } \\
\text { Mauritania }\end{array}$ & \\
\hline \multicolumn{3}{|l|}{ Guinea-Bisau $(\mathrm{d}<0)$} \\
\hline \multicolumn{3}{|l|}{ Upper-middle income } \\
\hline Cameroon & Congo-Brazzavile & Nigeria \\
\hline Côte d'Ivoire & Djibouti & \\
\hline Ghana & Egypt & \\
\hline Senegal & Kenya & \\
\hline \multirow[t]{3}{*}{ Swaziland } & Lesotho & \\
\hline & Sao Tomé \& Principe & \\
\hline & Zambia & \\
\hline \multicolumn{3}{|l|}{ High income } \\
\hline Gabon & Angola & South Africa \\
\hline Morocco & Botswana & Reunion \\
\hline \multirow[t]{6}{*}{ Namibia } & Cape Verde & Algeria \\
\hline & Equatorial Guinea & \\
\hline & Libya & \\
\hline & Mauritius & \\
\hline & Seychelles & \\
\hline & Tunisia & \\
\hline
\end{tabular}

Other things being equal, happiness is likely to be widespread when economic growth is robust, inflation rate is low and jobs are abundant (Hanke 2017).

The foregoing results can also be justified on the premise that African countries suffer some of the highest unemployment rates (Caporale and Gil-Alana 2018) and inflation in the globe (World Bank 2019). As a result, the continent has a very high rate of economic discomfort and economic hardships, which portend significant hindrances to several benefits that free market offers to its participants. Hence, it is not easy to instantly and significantly change misery index in the continent. 


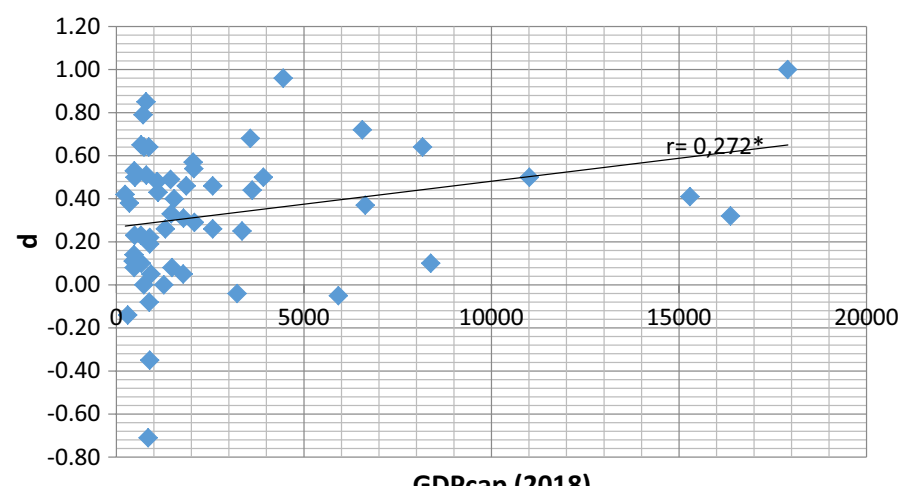

GDPcap (2018)

Fig. 1 Income and persistence of the misery index. *Significant correlation at level 0.05 (bilateral)

Another reason for the going results is due to the economic and structural deficiencies present in many African countries. These factors that ensure the continuous high unemployment and inflation include corruption, policy uncertainty, infrastructural deficiencies, weak currency growing ever weaker, high presence of the public sector and incompetent leadership. All these factors serve as hindrance to the policies aimed at addressing misery index including raising labour productivity by investment in education and training of the workforce, capital stock expansion, and the enhancement of business efficiency.

It is difficult to attribute the overwhelmingly evidence for stationarity to domination of either unemployment or inflation in the misery index although some studies link one of the two component to persistence or otherwise. Inflation rate series are likely to be mean reverting (Isoardi and Gil-Alana 2019), while unemployment rates figures are likely to lack mean reversion (Caporale and Gil-Alana 2018). We observe that inflation rates account for more than $50 \%$ of the misery index in 23 of the 47 countries with mean reverting misery index (Table 1). It is also observed that unemployment rates account for more than $50 \%$ of the misery index in 3 of the 8 countries with non-mean reverting misery index (Table 1).

\section{Concluding Comments}

In this paper we have examined the misery index in a group of 55 African countries by using fractional integration or I(d) tests. This methodology is very appropriate to measure the degree of persistence in time series in the sense that it is more general than other standard methods that only use integer degrees of differentiation and permits us to look at the mean reverting property of the data in a very flexible way.

Our results indicate that there exists a large degree of heterogeneity across the countries, with the values of $d$ moving from a significantly negative value in the case of Guinea Bissau (and thus showing anti-persistence) to the unit root case in eight countries (Nigeria, Gambia, Liberia, South Africa, Uganda, Sudan, Algeria and Reunion) (and thus showing permanency of shocks). Between these, we have a group of twenty-one countries showing I(0) or short memory behaviour (with shocks disappearing relatively fast): Chad, Burundi, Comoros, Namibia, Swaziland, Burkina Faso, Zimbabwe, Libya, Ghana, Senegal, Congo Democratic Republic, Gabon, Togo, Central African Republic, Madagascar, Mali, Somalia, 
Niger, Morocco, Côte d'Ivoire and Cameroon, and another group of twenty-five countries with long memory mean reverting behaviour (and with the effects of the shocks disappearing much slower: Ethiopia, Mauritania, Congo-Brazzavile, Djibouti, Seychelles, Lesotho, Libya, Mali, Equatorial Guinea, South Sudan, Eritrea, Cape Verde, Kenya, Egypt, Tanzania, Zambia, Mauritius and Sierra Leone, Angola, Rwanda, Mozambique, Sao Tome, Botswana, Guinea and Tunisia. Thus, we find a lot of heterogeneity in the group of countries examined. Moreover, we find a significant positive relation between the level of income of the countries and their degree of persistence. This final relationship will be more deeply examined in future papers.

The dominant mean reverting nature of the series implies that any policy changes will only have a temporary effect on the misery index. Hence, in order to address economic discomfort or hardship (which misery index represents), it is more appropriate to follow a gradual approach to reduce misery index levels, such that the average figure for the series is decreased over a period of time and the medium to long term figure start to rely more on these lower ones, until getting to a level at which the persistence stops being so high.

Since it is difficult to attribute the overwhelming evidence for mean reversion to the domination of either unemployment or inflation in the misery index, it will appropriate to use economic policies to boost aggregate supply rather than just focussing on strong expansionary (contractionary) monetary and fiscal policies to address both unemployment (inflation). For instance, improving the productivity of labour will reduce unemployment and inflation and ultimately improve (reduce) welfare (economic discomfort and unhappiness).

For the few countries with misery index not reverting to their mean levels and by implication, shocks resulting from new policies may persist for longer time periods. Hence, in these nations, robust policy actions are required to reduce misery index. Since three of the non-mean reverting countries are among the largest African economies (South Africa, Algeria and Nigeria), this implies that shocks are likely to influence the performance of the totality of the African economy.

In majority of the countries with mean reverting misery index, it will be possible to use forecasting as a basic tool for misery index as the previous values of the index can be employed to accurately project its future values. Moreover, the original series of misery index can be included in statistical analysis without the need to take their first differences. Statistical approaches including ordinary least squares (OLS) which are premised on the assumption that the variables are mean reversion will not generate spurious regression inferences due to any under-differencing problem.

Acknowledgements Luis A. Gil-Alana gratefully acknowledges financial support from the Ministerio de Ciencia y Tecnología ((ECO2017-85503-R). Comments from the Editor and two anonymous reviewers are gratefully acknowledged.

\section{References}

Akçay, S. (2018). Remittances and misery index in Turkey: Is there a link? Applied Economics Letters, 25(13), 895-899.

Alam, M. S., Shahbaz, M., \& Paramati, S. R. (2016). The role of financial development and economic misery on life expectancy: Evidence from post financial reforms in India. Social Indicators Research, $128(2), 481-497$.

Albulescu, C. T., \& Tiwari, A. K. (2018). Unemployment persistence in EU countries: New evidence using bounded unit root tests. Applied Economics Letters, 25(12), 807-810.

Ali, A., Mujahid, N., Rashid, Y., \& Shahbaz, M. (2015). Human capital outflow and economic misery: Fresh evidence for Pakistan. Social Indicators Research, 124(3), 747-764. 
Balcilar, M., Gupta, R., \& Jooste, C. (2016). Analyzing South Africa's inflation persistence using an ARFIMA model with Markov-switching fractional differencing parameter. The Journal of Developing Areas, 50(1), 47-57.

Barro, R. J. (1999). Reagan vs. Clinton: Who's the economic champ? Business Week, 22, 5.

Bentley, R. A., Acerbi, A., Ormerod, P., \& Lampos, V. (2014). Books average previous decade of economic misery. PLoS ONE, 9, e83147.

Bleaney, M., \& Francisco, M. (2005). Inflation persistence and exchange rate regimes: Evidence from developing countries. Economics Bulletin, 6(2), 1-15.

Bloomfield, P. (1973). An exponential model in the spectrum of a scalar time series. Biometrika, 60, 217-226.

Caporale, G. M., \& Gil-Alana, L. A. (2018). Unemployment in Africa: A fractional integration approach. South African Journal of Economics, 86(1), 76-81.

Cavanaugh, K. L., \& King, K. D. (1988). Simultaneous transfer function analysis of Okun's misery index: Improvements in the economic quality of life through Maharishi's vedic science and technology of consciousness. In Paper presented at the annual meeting of the American Statistical Association, New Orleans, Louisiana, August 22-25, 1988.

Cohen, I. K., Ferretti, F., \& McIntosh, B. (2014). Decomposing the misery index: A dynamic approach. Cogent Economic and Finance, 2, 1-8.

Dadgar, Y., \& Nazari, R. (2018). The impact of economic growth and good governance on misery index in Iranian economy. European Journal of Law and Economics, 45(1), 175-193.

Dahlhaus, R. (1989). Efficient parameter estimation for self-similar process. Annals of Statistics, 17, 1749-1766.

Di Tella, R., MacCulloch, R. J., \& Oswald, A. J. (2001). Preferences over inflation and unemployment: Evidence from surveys of happiness. American Economic Review, 91(1), 335-341.

Dickey, D. A., \& Fuller, W. A. (1979). Distributions of the estimators for autoregressive time series with a unit root. Journal of American Statistical Association, 74(366), 427-481.

Diebold, F. X., \& Rudebusch, G. D. (1991). On the power of Dickey-Fuller test against fractional alternatives. Economics Letters, 35(1), 155-160.

Elliot, G., Rothenberg, T. J., \& Stock, J. H. (1996). Efficient tests for an autoregressive unit root. Econometrica, 64, 813-836.

García-Cintado, A., Romero-Ávila, D., \& Usabiaga, C. (2015). Can the hysteresis hypothesis in Spanish regional unemployment be beaten? New evidence from unit root tests with breaks. Economic Modelling, 47, 244-252.

Gil-Alana, L. A. (2011). Inflation in South Africa. A long memory approach. Economics Letters, 111(3), 207-209.

Gil-Alana, L. A., Ozdemir, Z. A., \& Tansel, A. (2019). Long memory in Turkish unemployment rates. Emerging Markets Finance and Trade, 55(1), 201-217.

Gil-Alana, L. A., \& Robinson, P. M. (1997). Testing of unit roots and other nonstationary hypotheses in macroeconomic time series. Journal of Econometrics, 80, 241-268.

Gupta, R., Jooste, C. H., \& Ranjbar, O. (2017). South Africa's inflation persistence: A quantile regression framework. Economic Change and Restructuring, 50(4), 367-384.

Hanke, S. (2017). Misery index: The world's saddest (and happiest) countries. https://www.forbes.com/ sites/stevehanke/2017/02/09/misery-index-ranking-the-worlds-saddest-and-happiest-countries/\#165f7 cd14448. Accessed 1 June 2019.

Hasslers, U., \& Wolters, J. (1994). On the power of unit root tests against fractional alternatives. Economics Letters, 45(1), 1-5.

IMF. (Ed.). (2018). Report for selected countries and subjects. Consulted January 16, 2019.

Isoardi, M., \& Gil-Alana, L. A. (2019). Inflation in Argentina: Analysis of persistence using fractional integration. Eastern Economic Journal, 45(2), 204-223.

Kabundi, A., Sahaling, F., \& Somec, M. (2019). Estimating a Phillips curve for South Africa: A bounded random-walk approach. International Journal of Central Banking, 15, 75-100.

Kouassi, E., \& Sthlare, L. (2018). Unemployment persistence in Southern African countries: Further evidence from panel unit root tests. Studies Economics and Econometrics, 42(1), 115-134.

Kwiatkowski, D., Phillips, P. C. D., Schmidt, P., \& Shin, Y. (1992). Testing the null hypothesis of stationarity against the alternative of a unit root: How sure are we that economic time series have a unit root? Journal of Econometrics, 54, 159-178.

Lee, D., \& Schmidt, P. (1996). On the power of the KPSS test of stationarity against fractionally integrated alternatives. Journal of Econometrics, 73(1), 285-302.

Lobato, I. N., \& Velasco, C. (2007). Efficient Wald test for fractioanl unit roots. Econometric, 75(2), $575-589$. 
Lovell, M. C., \& Tien, P. L. (2000). Economic discomfort and consumer sentiment. Eastern Economic Journal, 26(1), 1-8.

Marvasti, M. B., Sadeghi, S. K., \& Karbor, R. (2014). New evidence of the link between income inequality and misery index. A nonlinear time series. International Journal of Sustainable Development and World Policy, Conscientia Beam, 3(1), 25-30.

Nessen, R. (2008). Arthur Okun father of the misery index. Washington, DC: The Brookings Institution.

$\mathrm{Ng}, \mathrm{S}$., \& Perron, P. (2001). Lag length selection and the construction of unit root tests with good size and power. Econometrica, 69, 1519-1554.

Nieswiadomy, M., \& Strazicich, M. C. (2004). Are political freedoms converging. Economic Inquiry, 42(2), 323-340.

Phillips, P. C. B., \& Perron, P. (1988). Testing for a unit root in time series regression. Biometrika, 75, 335-346.

Phillips, P. C. B., \& Schmidt, P. (1992). LM tests for a unit root in the presence of deterministic trends. Oxford Bulletin of Economics and Statistics, 54(3), 257-287.

Phiri, A. (2017). Changes in inflation persistence prior and subsequent to the subprime crisis: What are the implications for South Africa? Journal of Reviews on Global Economics, 6, 198-207.

Pikoko, V., \& Phiri, A. (2018). Is there hysteresis in South African unemployment? Evidence from the postrecessionary period. MPRA paper no. 83962. https://mpra.ub.uni-muenchen.de/83962/. Accessed 1 June 2019.

Rangasamy, L. (2009). Inflation persistence and core inflation: The case of South Africa. South African Journal of Economics, 77(3), 430-444.

Robinson, P. M. (1994). Efficient tests of nonstationary hypotheses. Journal of the American Statistical Association, 89, 1420-1437.

Robinson, P. M. (1995). Gaussian semiparametric estimation of long range dependence. Annals of Statistics, $23,1630-1660$.

Rosas, G., \& Manzetti, L. (2015). Reassessing the trade-off hypothesis: How misery drives the corruption effect on presidential approval. Electoral Studies, 39, 26-38.

Saboor, A., Sadiq, S., Khan, A. U., \& Hameed, G. (2017). Dynamic reflections of crimes, quasi democracy and misery index in Pakistan. Social Indicators Research, 133(1), 31-45.

Setterfield, M. (2009). An index of macroeconomic performance. International Review of Applied Economics, 23, 625-649.

Shahbaz, M., Loganathan, N., Mujahid, N., Ali, A., \& Nawaz, A. (2016). Determinants of life expectancy and its prospects under the role of economic misery: A case of Pakistan. Social Indicators Research, 126(3), 1299-1316.

Solarin, S., \& Anoruo, E. (2015). Nonlinearity and the unit root hypothesis for African per capita real GDP. International Economic Journal, 29(4), 617-630.

Tang, C. F., \& Lean, H. H. (2009). New evidence from the misery index in the crime function. Economics Letters, 102, 112-115.

Tule, K. M., Egbuna, E. N., Dada, E., \& Ebuh, G. U. (2017). A dynamic fragmentation of the misery index in Nigeria. Cogent Economics and Finance. https://doi.org/10.1080/23322039.2017.1336295.

Welsch, H. (2007). Macroeconomics and life satisfaction: Revisiting the "Misery Index". Journal of Applied Economics, 10(2), 237-251.

Wiseman, C. (1992). More on misery: How consistent are alternative indices? A comment. The American Economist, 36, 85-88.

Wolters, M. H., \& Tillmann, P. (2015). The changing dynamics of US inflation persistence: A quantile regression approach. Studies in Nonlinear Dynamics and Econometrics, 19(2), 161-182.

World Bank. (2019). World development indicators. Retrieved from www.data.worldbank.org. Accessed 1 June 2019.

Wu, P. C., Liu, S. Y., \& Pan, S. C. (2014). Does misery index matter for the persistence of health spending? Evidence from OECD countries. Social Indicators Research, 118, 893-910.

Yaya, O., Ogbonna, A., \& Mundida, R. (2019). Hysteresis of unemployment rates in Africa: New findings from Fourier ADF test. MPRA paper no. 93939. https://mpra.ub.uni-muenchen.de/93939. Accessed 1 June 2019.

Ying, Z., Dong, C. R., Chang, H. L., \& Su, C. W. (2014). Are real GDP levels stationary in African countries? South African Journal of Economics, 82(3), 392-401.

Publisher's Note Springer Nature remains neutral with regard to jurisdictional claims in published maps and institutional affiliations. 